İNALT

Vorwort . . . . . . . . . .................

\title{
HANS MOTTE
}

Einleitende Bemerkungen - Zum Verlauf und zu einigen Hauptproblemen der industriellen Revolution in Deutschland

I. Zum Weseñ der industriellen Revolution in England ... . . . . . . 11

II. Zur Vorbereitungsperiode der industriellen Revolution in Deutschland 18

III. Zur industriellen Revolution 1834 bis 1873 . . . . . . . . . . . . . 26

1. Zur Anlage von konstantem, fixen Kapital . . . . . . . . . . . 26

2. Zur Steigerung der Produktion. ... . . . . . . . . . . . 44

3. Zum produktionstechnischen Fortschritt in den kapitalistischen Industriebetrieben ................... . 48

4. Zur Entwicklung in den noch auf Handarbeit beruhenden Produktionszweigen ..................... . 52

5. Zur. Lage der Arbeiter in der industriellen Revolution Deutschlands $\mathbf{5 7}$

IV. Zur Frage der Beendigung der industriellen Revolution . . . . . . . . 61

HORST BLUMBERG

Ein Beitrag zur Geschichte der deutschen Leinenindustrie von 1834 bis 1870

I. Die allgemeine Entwicklung der Leinwandproduktion von 1834 bis 1870

II. Die Entwicklung des inneren und äußeren Marktes für die deutsche Leinenindustrie . . . . . . . . . . . . . . . . . . 81

1. Die Entwicklung des inneren Marktes für die deutsche Leinenindustrie $\mathbf{8 1}$

2. Díe Entwicklung des äußeren Harktes für die deutsche Leinenindustrie $\quad \mathbf{9 3}$

III. Die Produktionsverhältnisse in der Leinenindustrie . . . . . . . . . . 104

1. Die Produktionsverhältnisse in der Flachsspinnereì . . . . . . . . . 104

2. Die Produktionsverhältnisse in der Leinenweberei 114

IV. Die Leinenindustrie und die Herausbildung des deutschen Proletariats sowie die Lage der Arbeiter in der Leinenindustrie . . . . . . . . . . 124

1. Die Leinenindustrie und die Herausbildung des deutschen Proletariats 124

2. Die Lage der Arbeiter in der Leinenindustrie. . . . . 127

V. Schlußbetrachtung .................... 137 


\section{BBINZ WUTZMER}

Die Herkunft der industriellen Bourgeoisie Preußens in den vierziger Jahren des 19. Jahrhunderts . . . . . . . . . . . . . . . . . . 145

BORST BLUMBERG

Die Finanzierung der Neugründungen und Erweiterungen von Industriebetrieben in Form der Aktiengesellschaften wāhrend der fünfzigerJahre des 19. Jahrhunderts in Deutschland, am Beispiel der preußischen Verhältnisse erläutert

I. Zur Entwicklung von Industrie und Banken in den fünfziger Jahren 165

II. Zum Verhältnis Staat und Aktiengesellschaft in Preußen . . . . . . . 173

III. Die Ausnutzung der Form der Aktiengesellschaften für die Entwicklung der Industrie während der fünfziger Jahre des vorigen Jahrhunderts 177

IV. SchluBbetrachtung ................... 205

WALTER BECKER

Die Bedeutung der nichtagrarischen Wanderungen für die Herausbildung des industriellen Proletariats in Deutschlanન, unter besonderer Berūcksichtigung Preußens von 1850 bis 1870 . . . . . . . . . . . . . . . . . . 209 